\title{
Targeting novel coronavirus SARS-CoV-2 spike protein with phytoconstituents of Momordica charantia
}

\author{
Santosh Kumar Singh ${ }^{1,2}$, Shailesh Singh ${ }^{1,2}$ and Rajesh Singh ${ }^{1,2^{*}}$
}

\begin{abstract}
Background: Infections by the SARS-CoV-2 virus causing COVID-19 are presently a global emergency. The current vaccination effort may reduce the infection rate, but strain variants are emerging under selection pressure. Thus, there is an urgent need to find drugs that treat COVID-19 and save human lives. Hence, in this study, we identified phytoconstituents of an edible vegetable, Bitter melon (Momordica charantia), that affect the SARS-CoV-2 spike protein.

Methods: Components of Momordica charantia were tested to identify the compounds that bind to the SARS-CoV-2 spike protein. An MTiOpenScreen web-server was used to perform docking studies. The Lipinski rule was utilized to evaluate potential interactions between the drug and other target molecules. PyMol and Schrodinger software were used to identify the hydrophilic and hydrophobic interactions. Surface plasmon resonance (SPR) was employed to assess the interaction between an extract component (erythrodiol) and the spike protein.
\end{abstract}

Results: Our in-silico evaluations showed that phytoconstituents of Momordica charantia have a low binding energy range, -5.82 to $-5.97 \mathrm{kcal} / \mathrm{mol}$. A docking study revealed two sets of phytoconstituents that bind at the S1 and S2 domains of SARS-CoV-2. SPR showed that erythrodiol has a strong binding affinity $(K D=1.15 \mu \mathrm{M})$ with the S2 spike protein of SARS-CoV-2. Overall, docking, ADME properties, and SPR displayed strong interactions between phytoconstituents and the active site of the SARS-CoV-2 spike protein.

Conclusion: This study reveals that phytoconstituents from bitter melon are potential agents to treat SARS-CoV-2 viral infections due to their binding to spike proteins S1 and S2.

Keywords: Bitter melon, SARS-CoV-2, SPR, Erythrodiol, Momordica Charantia

\section{Background}

On January 30, 2020, the World Health Organization (WHO) declared infections of severe acute respiratory syndrome coronavirus 2 (SARS-CoV-2) a global emergency. Originating in Wuhan, China, in December 2019, the disease (COVID-19) took only four months to become a pandemic [1]. It has now spread to more than

\footnotetext{
*Correspondence: rsingh@msm.edu

${ }^{1}$ Department of Microbiology, Biochemistry and Immunology,

Morehouse School of Medicine, 720 Westview Drive SW, Atlanta, GA 30310, USA

Full list of author information is available at the end of the article
}

221 countries and territories [2]. With a scarcity of treatment options and lack of vaccines, especially in lowincome countries, COVID-19 has taken 4 million lives worldwide. This infection involves dosing with nucleoside analogs, such as remdesivir, that inhibit viral replication by becoming incorporated into RNA [3, 4]; others are supporting care, symptoms, experimental measures, and isolation. Repurposing of drugs and administering vaccines are believed to be promising to deal with this pandemic [5]. Given its drastic effects, many countries, including the United States, have employed extensive resources to find a definitive cure for COVID-19 and develop preventive vaccines. original author(s) and the source, provide a link to the Creative Commons licence, and indicate if changes were made. The images or other third party material in this article are included in the article's Creative Commons licence, unless indicated otherwise in a credit line to the material. If material is not included in the article's Creative Commons licence and your intended use is not permitted by statutory regulation or exceeds the permitted use, you will need to obtain permission directly from the copyright holder. To view a copy of this licence, visit http://creativecommons.org/licenses/by/4.0/. The Creative Commons Public Domain Dedication waiver (http://creativeco mmons.org/publicdomain/zero/1.0/) applies to the data made available in this article, unless otherwise stated in a credit line to the data. 
Scientific knowledge of the virus and COVID-19 are accumulating. However, treatment remains a challenge for physicians and patients. In a viral infection, the hostpathogen interaction is a critical step that can be utilized to develop antiviral therapy [6]. Further, cancer patients are more vulnerable to COVID-19 infections and, due to tumor-induced immune suppression, have a high frequency of severe symptoms [7].

Like Middle East respiratory syndrome coronavirus (MERS-CoV), SARS-CoV-2 has crossed the species barrier and has reached humans as deadly pneumonia [8]. Bats are considered the primary host for SARS-CoV-2, with palm civets and raccoon dogs as intermediate hosts $[9,10]$. The zoonotic transmission of SARS-CoV-2 between bats and humans remains to be described. SARS- CoV, which caused a previous outbreak of severe acute respiratory syndrome, and SARS-CoV-2 have the same origin, are structurally related with $80 \%$ genotypic similarity, and have the same binding affinities to human angiotensin-converting enzyme 2 (ACE2) [8, 11]. Like SARS-CoV, SARS-CoV-2 is a positive-strand virus with surface protein subunits $\mathrm{S} 1$ and $\mathrm{S} 2$ that bind to ACE2. In SARS-CoV-2, the spike glycoprotein ( $\mathrm{S}$ protein) is a trimeric protein that is cleaved into $\mathrm{S} 1$ and $\mathrm{S} 2$ subunits, of which S1 facilitates binding to the receptor, ACE2. $\mathrm{S} 2$ is cleaved by host proteases, mediates membrane fusion, and allows the virus to enter into host cells, an essential step in infection [12-15]. Structural studies of SARS-CoV-2 show that docking of the S protein trimer onto the structure of the ACE2 dimer suggests simultaneous binding of two $S$ protein trimers [16]. In addition, SARS-CoV-2 has a furin cleavage site between the S1 and S2 subunits that distinguishes SARS-CoV-2 from other SARS-CoVs [8]. Further, scanning electron micrograph studies show that monoclonal antibodies specific to the SARS-CoV receptor-binding domain (RBD) have no appreciable affinity to SARS-CoV-2, suggesting antibody cross-reactivity between the two viruses RBDs [17]. Thus, there is an urgent need to identify strategies that facilitate the development of decoy ligands to neutralize or suppress viral infection.

Natural products and their derivatives have been used to cure several diseases, including viral infections. A library of chemicals is available and needs to be explored to develop drugs to treat viral infections [18]. There are reports pointing to herbal medications and traditional medicine for treating SARS and other viral infections [19]. Among the sources of natural remedies, vegetables and fruits are rich sources of vitamins, dietary fiber, and minerals linked to reducing cardiovascular diseases, cancer, and other chronic diseases [20]. Among the vegetables, Momordica charantia, commonly known as bitter melon or bitter gourd, is consumed primarily in China,
India, and Pakistan. Bitter melon has many traditional uses, including treatment of nephropathy, neuropathy, gastroparesis, cataracts, and atherosclerosis. They are further inhibiting human immunodeficiency virus (HIV) from the compounds extracted from bitter melon, such as momordica anti-HIV protein (30 kDa, MAP-30) and gelonium anti-HIV protein (31 kDa, GAP-31). These compounds reduce viral infections in a concentrationdependent manner by inhibiting the HIV-1 integrase protein, remaining harmless to uninfected cells and unable to enter healthy cells [21, 22]. Moreover, among several compounds extracted from Momordica charantia, erythrodiol displayed potent anti-inflammatory and immunomodulatory activities and activity against HIV-1 reverse transcriptase $[23,24]$. Compounds that impede viral replication by binding to viral surface proteins could also exist, and these need to be identified.

In the present investigation, using molecular modeling and docking, we identified a natural compound from a bitter melon that could potentially block binding of the $\mathrm{S} 1$ and S2 proteins of $\mathrm{CoV}-2$ and thereby inhibit SARS$\mathrm{CoV}-2$ infections.

\section{Results \\ Molecular docking of phytoconstituents of bitter melon to SARS-CoV-2 S (spike protein)}

Binding energy ( $\mathrm{Kcal} / \mathrm{mol}$ ) data allow comparisons of the affinities of various ligands/compounds with their corresponding target receptor molecules. Lower binding energy indicates a higher affinity of the ligand for the receptor. The structure of the SARS-CoV-2 spike protein is shown in Fig. 1. The phytoconstituents of bitter melon (Momordica charantia) displayed low binding energies in the range of -5.82 to $-5.97 \mathrm{kcal} / \mathrm{mol}$ and similar binding preferences for the S2 domain of the spike protein (Fig. 2). However, momordicine I, cycloartenol, and vicine are bound to the $\mathrm{N}$-terminal of the $\mathrm{S} 1$ domain. Despite having a similar preference for the S2 and S1 domains, an additional hydroxyl group on the chromone ring of various constituents of bitter melon affected its hydrogen-bonding interactions with various residues of the S2 and S1 domains. As shown in Figs. 2 and 3, momordicine I interacted with the S1 spike domain through PHE374, SER373, SER371, LEU368, PHE338, GLY339, PHE342, and ASN343 residues through $\mathrm{H}$-bonding and hydrophobic interactions (based on 3D views of different - $\mathrm{OH}$ groups forming $\mathrm{H}$-bonds). Similarly, momordicine-II interacted with THR286, ASP287, ALA288, VAL289, ASP290, LEU293, ASP294, LEU296, and SER297; multiflorenol with GLN872, SER876, PRO807, LEU806, ILE788, TYR789, LYS790, THR791, and PRO793; stigmasterol with ILE788, TYR789, LYS790, THR791, PRO807, LEU806, LYS795, GLN872, 


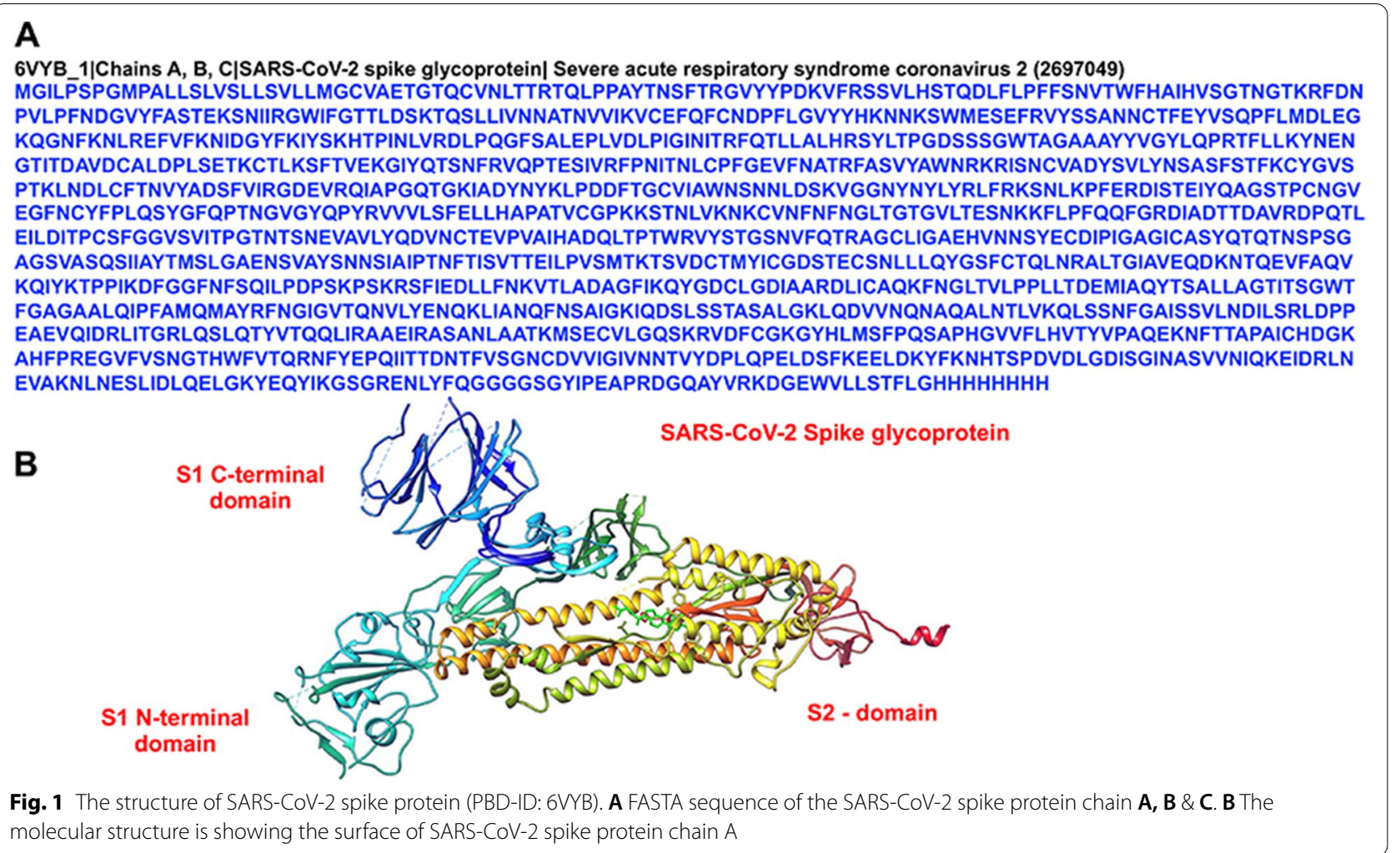

and SER875; campesterol with GLY1059, HID1058, PRO1057, ALA1056, SER1055, ILE870, ASP867, LEU865, and PRO863; charine with ILE870, PHE782, THR778, VAL729, SER730, MET731, THR732, LYS733, and PRO863; cryptoxanthin with PHE856, ASN856, VAL860; PRO863, LEU865, THR866, ASP867, and ILE870; cycloartenol with VAL367, LEU368, SER371, SER373, PHE374, TRP436, ASN437, SER438, and ASN439; erythrodiol with VAL860, PRO863, ASP867, ILE870, THR732, SER730, GLY1059, PRO1057, and ALA1056; and vicine with LEU368, VAL367, TYR365, ASP364, ALA363, VAL362, CYS336, PRO337, and PHE338. Overall, the docking study disclosed two distinct sets of ligands that bind at the S1 and S2 domains of the SARS-CoV-2 spike protein.

\section{Absorption, distribution, metabolism, and excretion (ADME) profiling of the phytoconstituents}

The Lipinski rule of five $[25,26]$, which is often used to evaluate potential interactions between candidate drugs and target molecules, evaluates the propensity of a compound with a notable pharmacological or biological activity to be used as a potential drug. The rule serves as a filter to screen potential therapeutic agents/drugs at the program's initiation, thereby minimizing the labor and cost of exercises involving clinical drug development and, to a large extent, preventing late-stage clinical failures. The rule mainly determines the various molecular properties of a compound that are its prime characteristics to be a potential drug. Lipinski's rule states that, for any compound to be selected as a potential drug, it should have (a) a molecular mass $<500$ daltons, (b) high lipophilicity (expressed as $\log \mathrm{P}<5$ ), (c) less than 5 hydrogen bond donors, (d) less than 10 hydrogen bond acceptors, and (e) a molar refractivity between 40-130. If a compound of interest possesses more than two of the abovementioned criteria, it is likely to be a candidate for drug development. The phytochemicals used in this study passed all five of Lipinski's criteria (Table 1). Thus, we suggest that these phytochemicals have the potential capacity to function effectively as drugs.

\section{Identification of the erythrodiol and SARS-CoV-2 spike protein S2 interaction}

Assessment of the binding kinetics and affinities between molecules is a well-established practice in drug development. Among advances in technology related to drug and receptor interaction, surface plasmon resonance (SPR) is a label-free technique that can monitor the real-time the association $\left(k_{\text {on }}\right)$ and dissociation $\left(k_{\text {off }}\right)$ rate constant) molecular interactions. SPR is also used as a tool in a wide variety of interactions of biomolecules, including 


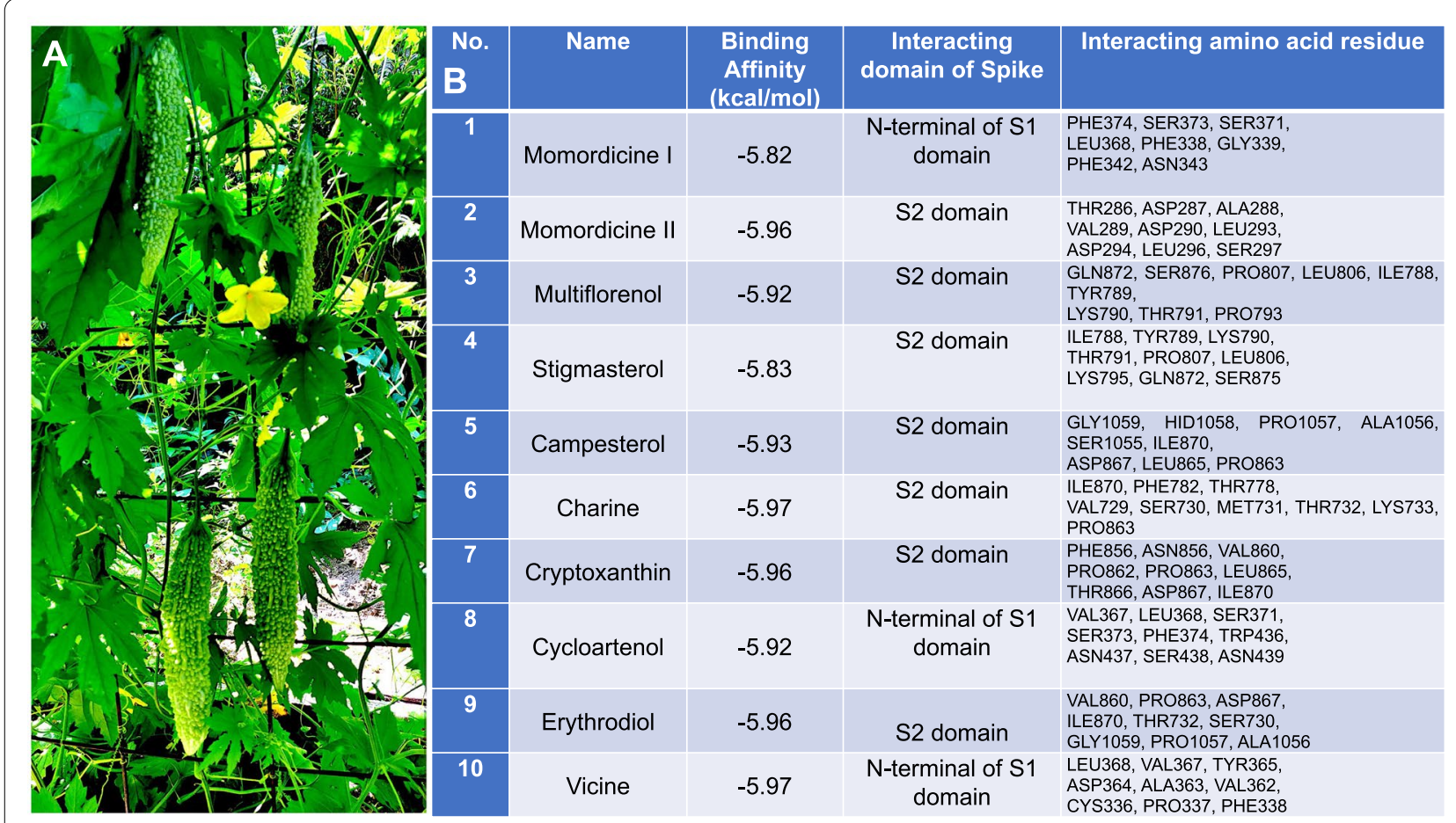

Fig. 2 Interaction of phytoconstituents of bitter melon with the domain of spike protein: A Bitter melon (Momordica charantia) plants. B Table shows the docking results of hydrogen bonding interaction between phytoconstituents to the active site of SARS-CoV-2 spike protein S1 and S2

small molecules, nucleic acids, carbohydrates, lipids, ligand-receptor kinetics, antibody-antigen interactions, enzyme-substrate reactions, and epitope mapping [2730]. To confirm the binding affinity between erythrodiol and the S2 spike protein, we employed $\mathrm{COOH}$ sensor chip-based SPR. A typical SPR signal from experimental data at various analyte concentrations is shown in Fig. 4. Our results showed that the S2 spike protein bound to erythrodiol with a high association rate constant, $\mathrm{ka}=1.93 \times 10^{3} \mathrm{M}^{-1} \mathrm{~S}^{-1}$; the dissociation rate constant was $\mathrm{kd}=2.21 \times 10^{-3} \mathrm{~S}^{-1}$. The binding kinetics showed an equilibrium dissociation constant (KD) value of $1.15 \mu \mathrm{M}$. In sum, erythrodiol displayed a strong interaction with the SARS-CoV-2 spike S2 protein.

\section{Discussion}

COVID-19 outbreaks are threats to human beings across the globe. Scientists, clinicians, and researchers are working to develop effective treatments for the highly contagious coronavirus strains. To date, several compounds are being screened for potency and selectivity before conducting human trials. In computer-aided drug design, particularly for identifying a lead compound [31, 32], molecular docking is employed to explore the various types of binding interactions of prospective drugs with various domains or active sites of the target molecules.
The interactions include H-bond, $\pi-\pi$, and amide- $\pi$ interactions. The binding affinity of a ligand with an active site has been determined by evaluating its hydrogen-bonding pattern [31,33] and the nature of residues present at the active site. The binding energy $(\mathrm{Kcal} / \mathrm{mol})$ data allow comparisons of the binding affinity of various ligands/ compounds with their corresponding target receptor molecules. A lower binding energy indicates a higher affinity of the ligand to the receptor. Ligands with high affinities can be selected as potential drugs.

Natural compounds derived from plant extracts are assets in identifying new drugs. To date, only a few natural compounds have been identified as therapeutic with specificity for cellular and molecular targets. For instance, Taxol binds to $\beta$-tubulin, which distorts the cytoskeleton framework and causes cell-cycle arrest and, subsequently, cell death, has been used for several decades to treat various tumors [34]. Furthermore, natural compounds exhibit a myriad of biological activities, including antiviral activity. A virtual screening study demonstrates that natural compounds can inhibit the binding of SARSCoV-2 to ACE2 [35]. Here, we investigated the effect of biomolecule extracted from Momordica charantia to block the SARS-CoV-2 spike protein, which is necessary for SARS-CoV-2 infection. Components from Momordica charantia exhibit immunosuppressive as well as 

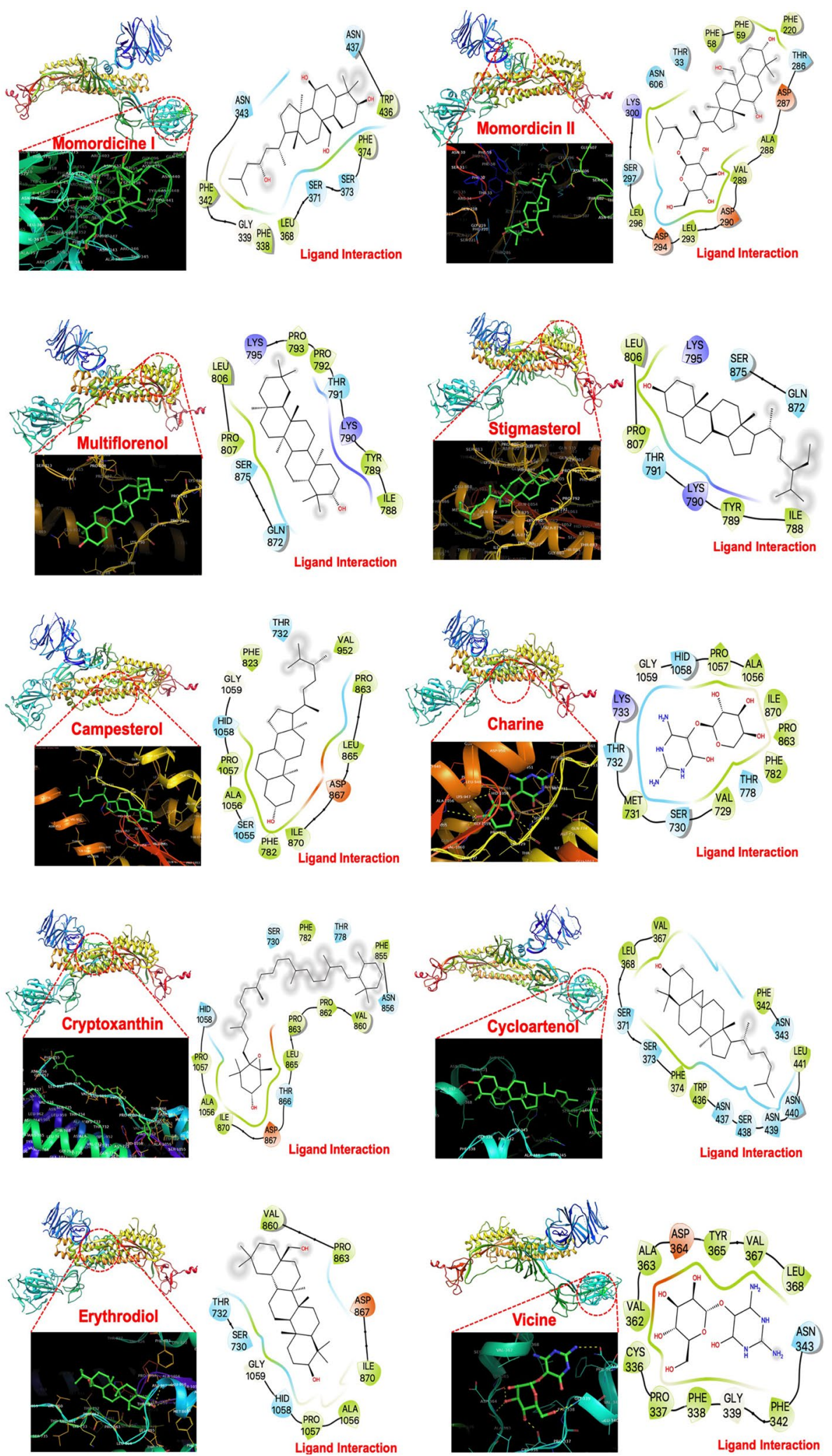

Fig. 3 The molecular docking of SARS-CoV-2 spike protein and bitter melon phytoconstituents: The 3-dimensional ribbon structure of SARS-CoV-2 spike protein and stick model of bitter melon phytoconstituents showing the binding site of the SARS-CoV-2 spike protein. The LigPlot structure is showing the interaction with amino acid residues of SARS-CoV-2 spike protein 
Table 1 ADME Properties of selected bitter melon (Momordica charantia) phytoconstituents against SARS-CoV-2 spike protein

\begin{tabular}{|c|c|c|c|c|c|}
\hline No. & Name & Chemical Structure & $\begin{array}{c}\text { ADME Properties } \\
\text { (Lipinki's Rule) }\end{array}$ & Value & $\begin{array}{c}\text { Drug } \\
\text { Likeliness } \\
\end{array}$ \\
\hline 1 & Momordicine I & & $\begin{array}{l}\text { Molecular Weight }(<=500 \mathrm{Da}) \\
\operatorname{LogP}(<=5) \\
\text { H-Bond donar }(<=5) \\
\text { H-Bond acceptor }(<=10) \\
\text { Molar refractivity }(40-130)\end{array}$ & $\begin{array}{c}472 \\
5.45 \\
3 \\
4 \\
135\end{array}$ & Yes \\
\hline 2 & Momordicine II & & $\begin{array}{l}\text { Molecular Weight }(<=500 \mathrm{Da}) \\
\text { LogP }(<=5) \\
\text { H-Bond donar }(<=5) \\
\text { H-Bond acceptor }(<=10) \\
\text { Molar refractivity }(40-130)\end{array}$ & $\begin{array}{c}634 \\
3.28 \\
6 \\
9 \\
168 \\
\end{array}$ & NO \\
\hline 3 & Multiflorenol & & $\begin{array}{l}\text { Molecular Weight }(<=500 \mathrm{Da}) \\
\text { LogP }(<=5) \\
\text { H-Bond donar }(<=5) \\
\text { H-Bond acceptor }(<=10) \\
\text { Molar refractivity }(40-130)\end{array}$ & $\begin{array}{c}426.72 \\
8.16 \\
1 \\
1 \\
130 \\
\end{array}$ & Yes \\
\hline 4 & Stigmasterol & & $\begin{array}{l}\text { Molecular Weight }(<=500 \mathrm{Da}) \\
\text { LogP }(<=5) \\
\text { H-Bond donar }(<=5) \\
\text { H-Bond acceptor }(<=10) \\
\text { Molar refractivity }(40-130)\end{array}$ & $\begin{array}{c}412.70 \\
7.80 \\
1 \\
1 \\
128 \\
\end{array}$ & Yes \\
\hline 5 & Campesterol & & $\begin{array}{l}\text { Molecular Weight }(<=500 \mathrm{Da}) \\
\text { LogP }(<=5) \\
\text { H-Bond donar }(<=5) \\
\text { H-Bond acceptor }(<=10) \\
\text { Molar refractivity }(40-130)\end{array}$ & $\begin{array}{c}400.69 \\
7.63 \\
1 \\
1 \\
123 \\
\end{array}$ & Yes \\
\hline 6 & Charine & & $\begin{array}{l}\text { Molecular Weight }(<=500 \mathrm{Da}) \\
\operatorname{LogP}(<=5) \\
\text { H-Bond donar }(<=5) \\
\text { H-Bond acceptor }(<=10) \\
\text { Molar refractivity }(40-130)\end{array}$ & $\begin{array}{c}274.23 \\
-3.24 \\
6 \\
9 \\
59 \\
\end{array}$ & Yes \\
\hline 7 & Cryptoxanthin & 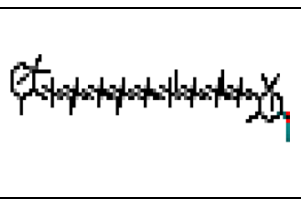 & $\begin{array}{l}\text { Molecular Weight }(<=500 \mathrm{Da}) \\
\operatorname{LogP}(<=5) \\
\text { H-Bond donar }(<=5) \\
\text { H-Bond acceptor }(<=10) \\
\text { Molar refractivity }(40-130)\end{array}$ & $\begin{array}{c}568.88 \\
10.78 \\
1 \\
2 \\
182 \\
\end{array}$ & NO \\
\hline 8 & Cycloartenol & & $\begin{array}{l}\text { Molecular Weight }(<=500 \mathrm{Da}) \\
\text { LogP }(<=5) \\
\text { H-Bond donar }(<=5) \\
\text { H-Bond acceptor }(<=10) \\
\text { Molar refractivity }(40-130)\end{array}$ & $\begin{array}{c}426.72 \\
8.16 \\
1 \\
1 \\
130 \\
\end{array}$ & Yes \\
\hline 9 & Erythrodiol & & $\begin{array}{l}\text { Molecular Weight }(<=500 \mathrm{Da}) \\
\text { LogP }(<=5) \\
\text { H-Bond donar }(<=5) \\
\text { H-Bond acceptor }(<=10) \\
\text { Molar refractivity }(40-130)\end{array}$ & $\begin{array}{c}442.72 \\
7.14 \\
2 \\
2 \\
132 \\
\end{array}$ & Yes \\
\hline 10 & Vicine & & $\begin{array}{l}\text { Molecular Weight }(<=500 \mathrm{Da}) \\
\text { LogP }(<=5) \\
\text { H-Bond donar }(<=5) \\
\text { H-Bond acceptor }(<=10) \\
\text { Molar refractivity }(40-130)\end{array}$ & $\begin{array}{c}304.25 \\
-3.88 \\
7 \\
10 \\
65 \\
\end{array}$ & Yes \\
\hline
\end{tabular}




\section{Kinetics Evaluation (Erythrodiol)}

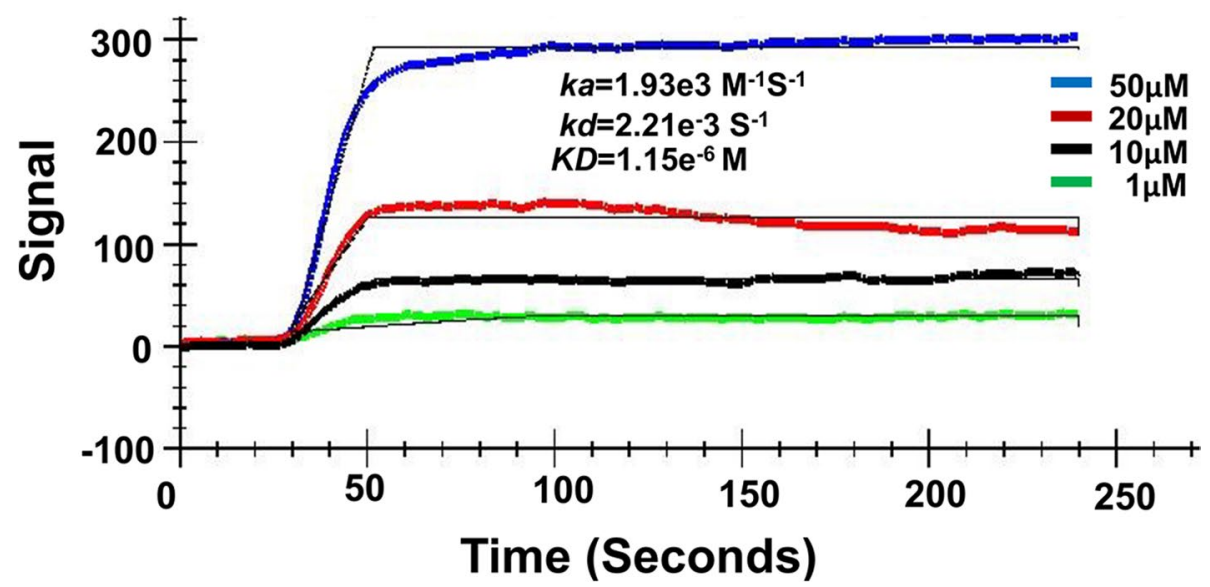

Fig. 4 Binding kinetics analysis of SARS-CoV-2 spike protein and the bitter melon phytoconstituent, erythrodiol. Surface plasmon resonance (SPR) sensogram showing the binding kinetics for immobilized SARS-CoV-2 spike protein S2 and the bitter melon phytoconstituent, erythrodiol. A typical response curve at different analyte concentrations (green, $1 \mu \mathrm{M}$; black, $10 \mu \mathrm{M}$; red, $20 \mu \mathrm{M}$; blue, $50 \mu \mathrm{M}$ ) shows the association $(\mathrm{ka}=1.93 \times 103 \mathrm{M}-1 \mathrm{~S}-1)$ and dissociation $(\mathrm{kd}=2.21 \times 10-3 \mathrm{~S}-1)$ rate constant of interaction. A binding affinity between SARS-CoV-2 spike protein S2 and erythrodiol showed an equilibrium dissociation constant $(K D)$ value, $1.15 \mu \mathrm{M}$. Data sets were analyzed by one-to-one (1:1) binding fit models using TraceDrawer evaluation software

immunostimulatory activity. The immunosuppressive activity of alpha- and beta-momorcharin is due to lymphocytotoxicity or to a shift in the kinetic parameters of the immune response [36]. In contrast to this, other studies have shown that this compound potentiates the immune system by increasing natural killer cell numbers and cytotoxic activity [37]. At doses of 25, 50, and $100 \mathrm{mg} / \mathrm{kg}$ body weight, an ethanolic extract showed a stimulatory effect on both humoral and cellular functions in vivo [38]. Furthermore, the immunomodulatory activity of Momordica charantia fruits and seeds is attributed to their property of inhibiting the release of TNF- $\alpha$ and nitric oxide (NO) [38].

Erythrodiol, a precursor of pentacyclic triterpenic acids, displays activity against HIV-1 reverse transcriptase with an IC50 of $5 \mu \mathrm{M}$ [24]. To characterize the binding interaction between erythrodiol and SARS-CoV-2 spike protein S2, we employed SPR, which has been used to screen interactions between potential drugs and their receptors. Our results demonstrate that erythrodiol has high selectively (binding affinity $1.15 \mu \mathrm{M}$ ) and inhibitory activity for SARS-CoV-2 spike protein S2. This is supported by the fact that SPR technology has been used to screen a library of 960 compounds for binding to ACE2 [5].

\section{Conclusions}

An in-silico approach to finding a natural compound that binds and prevents the attachment/internalization of the SARS-CoV-2 virus is a therapeutic and preventive option for the development of drugs with a time constraint. Bioinformatics approaches to make a fast and more or less accurate predictions for potential drugs or inhibitors. In this study, we used multiple bioinformatics tools to identify potent natural compounds, mainly flavonoids, that target and bind to the spike protein of SARS-CoV-2. We identified 10 flavonoids capable of binding either to the $\mathrm{S} 1$ or S2 domain of the SARS-CoV-2 protein. Our findings suggest that compounds from Momordica charantia have the potential to inhibit the SARS-CoV-2 spike protein and should be explored further as agents for preventing COVID-19.

\section{Materials and methods}

\section{Ligands and Receptor}

The 3-dimensional structures of phytoconstituents of bitter melon (Momordica charantia) were downloaded from the PubChem database, and these structures were converted to a Protein Data Bank (PDB) format by use of chimera software. The structure of SARS-CoV-2 S (spike protein) (Fig. 1) was downloaded from the RCSB protein data bank (PDB-ID: 6VYB) [8]. The structures of the ligands are provided in Table 1.

Molecular docking of bitter melon (Momordica charantia) phytoconstituents to the SARS-CoV-2 spike protein

The structure of SARS-CoV-2 spike protein was used for the docking analysis. SARS-CoV-2 spike protein is a heterotrimer consisting of chains $\mathrm{A}, \mathrm{B}$, and $\mathrm{C}$ [8]. For 
the docking experiment, chain A of the spike protein was used. All the docking experiment was performed using MTiOpenScreen web server. First, the SARS-CoV-2 spike protein file was uploaded with respective bitter melon (Momordica charantia) phytoconstituents, and then virtual screening was performed using AutoDock Vina [39], with employs a gradient-based conformational search. AutoDock defines the search space by a grid box defined by the box center coordinates with its dimensions of $x, y$, and $\mathrm{z}$. In AutoDock Vina, the grid resolution is internally assigned to $1 \AA$. We used the number of binding modes of 10 and exhaustiveness of 8 . The grid dimensions and center provided were automatically calculated based on the protein residues of the binding site. The scoring of the generated docking poses and ranking of the ligands were based on the Vina empirical scoring function and approximated the $\mathrm{kcal} / \mathrm{mol}$ 's binding affinity. The hydrophilic and hydrophobic interactions were determined using PyMol and Schrodinger software.

\section{Prediction of ADME analysis}

ADME profiling of the phytoconstituents was determined using online software tools at $\mathrm{pH} 7$ [25]. The essential parameters allied with ADME properties, such as Lipinski's rule of five and the drug's solubility, pharmacokinetic properties, molar refractivity, and likeliness, were deliberated [26]. All calculated values are shown in Table 1.

\section{Surface plasmon resonance (SPR) signal detection in SARS-CoV-2 spike protein and erythrodiol binding}

Following our previous publication [40], we investigated the binding interaction between SARS-CoV-2 spike protein and erythrodiol using an OpenSPR instrument (Nicoya Lifescience, ON, Canada). Briefly, for covalent coupling, the first carboxyl $(\mathrm{COOH})$ sensor chip was loaded into the instrument and pumped with running buffer 1X PBS (pH 7.4). Next, the amine coupling kit EDC:1-(3-dimethylaminopropyl)-3-ethylcarbodiimide hydrochloride; NHS: N-hydroxysuccinimide (EDC/ NHS) was applied as described in the manufacturer's protocol. Further, a ligand, recombinant protein SARSCoV-2 spike protein S2 $(50 \mu \mathrm{g} / \mathrm{mL}$, Fisher Scientific, PA, USA) was diluted in activation buffer and immobilized on a sensor chip. After 5 min of interaction, it was blocked with a blocking buffer supplied by the manufacturer (Nicoya Lifescience, ON, Canada), followed by the blank buffer. Subsequently, various concentrations $(1 \mu \mathrm{M}-50 \mu \mathrm{M})$ of analyte erythrodiol (Fisher Scientific, PA, USA) were injected onto the ligand-immobilized sensor chip with a flow rate of $20 \mu \mathrm{L} / \mathrm{min}$. Further, to assess the interaction, the buffer blank generated by the flow cell was subtracted, and the data sets were analyzed by one-to-one (1:1) binding fit models using Trace Drawer software.

\section{Abbreviations}

SARS-CoV-2: Severe acute respiratory syndrome coronavirus 2; ACE 2: Angiotensin-converting enzyme 2; RBD: Receptor-binding domain; HIV: Human immunodeficiency virus; ADME: Absorption, distribution, metabolism, and excretion; SPR: Surface plasmon resonance; KD: Equilibrium dissociation constant; TNF: Tumor necrosis factor; PDB: Protein data bank; RCSB PDB: Research Collaboratory for Structural Bioinformatics Protein Data Bank.

\section{Acknowledgements \\ We thanks to Donald L. Hill for the editing and proofreading of the manuscript.}

\section{Authors' contributions}

SKS and RS performed the experiments, analyzed the data, and prepared the manuscript. SS contributed to the idea development and discussed the experiments, and critically reviewed and edited the manuscript. RS conceived the idea and designed the experiments, critically reviewed and finalized the manuscript, and provided infrastructure and research facilities to perform the experiments. All authors read and approved the manuscript.

\section{Funding}

This study was supported by the National Cancer Institute of the National Institutes of Health under award numbers SC1CA193758 and U54CA118638 and by the Department of Defense under award number W81XWH1810429.

Availability of data and materials

All datasets analyzed during this study are included in the article.

\section{Declarations}

Ethics approval and consent to participate

Not applicable.

\section{Consent for publication}

Not applicable.

\section{Competing interests}

The authors declare that they have no competing interests.

\section{Author details}

${ }^{1}$ Department of Microbiology, Biochemistry and Immunology, Morehouse School of Medicine, 720 Westview Drive SW, Atlanta, GA 30310, USA. ${ }^{2}$ Cancer Health Equity Institute, Morehouse School of Medicine, 720 Westview Drive SW, Atlanta, GA 30310, USA.

Received: 23 July 2021 Accepted: 27 August 2021

Published online: 27 September 2021

\section{References}

1. Gostin LO. COVID-19 Reveals urgent need to strengthen the World Health Organization. JAMA. 2020;323(23):2361-2.

2. Pettersson H. Tracking Covid-19's global spread. 2020.

3. V'Kovski P, Kratzel A, Steiner S, Stalder H, Thiel V. Coronavirus biology and replication: implications for SARS-CoV-2. Nat Rev Microbiol. 2021;19(3):155-70.

4. Hu B, Guo H, Zhou P, Shi ZL. Characteristics of SARS-CoV-2 and COVID-19. Nat Rev Microbiol. 2021;19(3):141-54.

5. Zhu ZL, Qiu XD, Wu S, Liu YT, Zhao T, Sun ZH, et al. Blocking Effect of Demethylzeylasteral on the Interaction between Human ACE2 Protein and SARS-CoV-2 RBD Protein Discovered Using SPR Technology. Molecules. 2020;26(1):57.

6. Bupp K, Roth MJ. Alteration and analyses of viral entry with libraryderived peptides. Adv Virus Res. 2005;65:147-72. 
7. Dai M, Liu D, Liu M, Zhou F, Li G, Chen Z, et al. Patients with cancer appear more vulnerable to SARS-CoV-2: a multicenter study during the COVID-19 outbreak. Cancer Discov. 2020;10(6):783-91.

8. Walls AC, Park YJ, Tortorici MA, Wall A, McGuire AT, Veesler D. Structure, function, and antigenicity of the SARS-CoV-2 spike glycoprotein. Cell. 2020;181(2):281-92.e6.

9. Guan Y, Zheng BJ, He YQ, Liu XL, Zhuang ZX, Cheung CL, et al. Isolation and characterization of viruses related to the SARS coronavirus from animals in southern China. Science. 2003:302(5643):276-8.

10. Kan B, Wang M, Jing H, Xu H, Jiang X, Yan M, et al. Molecular evolution analysis and geographic investigation of severe acute respiratory syndrome coronavirus-like virus in palm civets at an animal market and on farms. J Virol. 2005;79(18):11892-900.

11. Zhou P, Yang XL, Wang XG, Hu B, Zhang L, Zhang W, et al. A pneumonia outbreak associated with a new coronavirus of probable bat origin. Nature. 2020;579(7798):270-3.

12. Simmons G, Zmora P, Gierer S, Heurich A, Pöhlmann S. Proteolytic activation of the SARS-coronavirus spike protein: cutting enzymes at the cutting edge of antiviral research. Antiviral Res. 2013;100(3):605-14.

13. Belouzard S, Chu VC, Whittaker GR. Activation of the SARS coronavirus spike protein via sequential proteolytic cleavage at two distinct sites. Proc Natl Acad Sci U S A. 2009;106(14):5871-6.

14. Li F, Li W, Farzan M, Harrison SC. Structure of SARS coronavirus spike receptor-binding domain complexed with receptor. Science. 2005;309(5742):1864-8.

15. Millet JK, Whittaker GR. Host cell proteases: Critical determinants of coronavirus tropism and pathogenesis. Virus Res. 2015;202:120-34.

16. Yan R, Zhang Y, Li Y, Xia L, Guo Y, Zhou Q. Structural basis for the recognition of SARS-COV-2 by full-length human ACE2. Science. 2020;367(6485):1444-8.

17. Wrapp D, Wang N, Corbett KS, Goldsmith JA, Hsieh CL, Abiona O, et al. Cryo-EM structure of the 2019-nCoV spike in the prefusion conformation. Science. 2020;367(6483):1260-3.

18. Islam MT, Sarkar C, El-Kersh DM, Jamaddar S, Uddin SJ, Shilpi JA, et al. Natural products and their derivatives against coronavirus: a review of the non-clinical and pre-clinical data. Phytother Res. 2020;34(10):2471-92.

19. Li SY, Chen C, Zhang HQ, Guo HY, Wang H, Wang L, et al. Identification of natural compounds with antiviral activities against SARS-associated coronavirus. Antiviral Res. 2005;67(1):18-23.

20. Naeem MY, Ozgen S, Amin K, Selamoglu Z. Antidotic potency of bitter gourd (Momordica charantia L). J Tradit Med Clin Natur. 2018;7(2):268.

21. Lee-Huang S, Huang PL, Huang PL, Bourinbaiar AS, Chen HC, Kung HF. Inhibition of the integrase of human immunodeficiency virus (HIV) type 1 by anti-HIV plant proteins MAP30 and GAP31. Proc Natl Acad Sci U S A. 1995;92(19):8818-22.

22. Lee-Huang S, Huang PL, Nara PL, Chen HC, Kung HF, Huang P, et al. MAP 30: a new inhibitor of HIV-1 infection and replication. FEBS Lett. 1990;272(1-2):12-8.

23. Martin R, Hernandez M, Cordova C, Nieto ML. Natural triterpenes modulate immune-inflammatory markers of experimental autoimmune encephalomyelitis: therapeutic implications for multiple sclerosis. Br J Pharmacol. 2012;166(5):1708-23.

24. Hisham Shady N, Youssif KA, Sayed AM, Belbahri L, Oszako T, Hassan HM et al. Sterols and Triterpenes: Antiviral Potential Supported by In-Silico Analysis. Plants (Basel). 2020;10(1):41.
25. Jayaram B, Singh T, Mukherjee G, Mathur A, Shekhar S, Shekhar V. Sanjeevini: a freely accessible web-server for target directed lead molecule discovery. BMC Bioinformatics. 2012;13(Suppl 17):S7.

26. Lipinski CA. Lead- and drug-like compounds: the rule-of-five revolution Drug Discov Today Technol. 2004;1(4):337-41.

27. Schuck P. Use of surface plasmon resonance to probe the equilibrium and dynamic aspects of interactions between biological macromolecules. Annu Rev Biophys Biomol Struct. 1997;26:541-66.

28. Cooper MA. Optical biosensors in drug discovery. Nat Rev Drug Discov. 2002;1(7):515-28.

29. Wittenberg NJ, Wootla B, Jordan LR, Denic A, Warrington AE, Oh SH, et al. Applications of SPR for the characterization of molecules important in the pathogenesis and treatment of neurodegenerative diseases. Expert Rev Neurother. 2014;14(4):449-63.

30. Nguyen HH, Park J, Kang S, Kim M. Surface plasmon resonance: a versatile technique for biosensor applications. Sensors (Basel). 2015;15(5):10481-510.

31. Raj S, Sasidharan S, Dubey VK, Saudagar P. Identification of lead molecules against potential drug target protein MAPK4 from L. donovani: An in-silico approach using docking, molecular dynamics and binding free energy calculation. PLoS ONE. 2019;14(8):e0221331.

32. Hughes JP, Rees S, Kalindjian SB, Philpott KL. Principles of early drug discovery. Br J Pharmacol. 2011;162(6):1239-49.

33. Chen D, Oezguen N, Urvil P, Ferguson C, Dann SM, Savidge TC. Regulation of protein-ligand binding affinity by hydrogen bond pairing. Sci Adv. 2016;2(3):e1501240.

34. Han L, Xu D, Xi Z, Wu M, Nik Nabil WN, Zhang J, et al. The natural compound oblongifolin c exhibits anticancer activity by inhibiting HSPA8 and cathepsin B in vitro. Front Pharmacol. 2020;11:564833.

35. Wu C, Liu Y, Yang Y, Zhang P, Zhong W, Wang Y, et al. Analysis of therapeutic targets for SARS-CoV-2 and discovery of potential drugs by computational methods. Acta Pharm Sin B. 2020;10(5):766-88.

36. Leung $\mathrm{SO}$, Yeung HW, Leung KN. The immunosuppressive activities of two abortifacient proteins isolated from the seeds of bitter melon (Momordica charantia). Immunopharmacology. 1987;13(3):159-71.

37. Cunnick JE, Sakamoto K, Chapes SK, Fortner GW, Takemoto DJ. Induction of tumor cytotoxic immune cells using a protein from the bitter melon (Momordica charantia). Cell Immunol. 1990;126(2):278-89.

38. Bortolotti M, Mercatelli D, Polito L. Momordica charantia, a nutraceutical approach for inflammatory related diseases. Front Pharmacol. 2019;10:486.

39. Trott O, Olson AJ. AutoDock Vina: improving the speed and accuracy of docking with a new scoring function, efficient optimization, and multithreading. J Comput Chem. 2010;31(2):455-61.

40. Singh SK, Gordetsky JB, Bae S, Acosta EP, Lillard JW, Jr., Singh R. Selective targeting of the hedgehog signaling pathway by PBM nanoparticles in docetaxel-resistant prostate cancer. Cells. 2020;9(9):1976.

\section{Publisher's Note}

Springer Nature remains neutral with regard to jurisdictional claims in published maps and institutional affiliations.

Ready to submit your research? Choose BMC and benefit from

- fast, convenient online submission

- thorough peer review by experienced researchers in your field

- rapid publication on acceptance

- support for research data, including large and complex data types

- gold Open Access which fosters wider collaboration and increased citations

- maximum visibility for your research: over 100M website views per year

At BMC, research is always in progress.

Learn more biomedcentral.com/submissions 